OPEN ACCESS

Edited by:

Zisis Kozlakidis,

International Agency for Research on

Cancer (IARC), France

Reviewed by:

Charles J. Vukotich,

University of Pittsburgh, United States

Holly Seale,

University of New South

Wales, Australia

${ }^{*}$ Correspondence:

Jonathan Kantor

jonkantor@gmail.com

Specialty section:

This article was submitted to Infectious Diseases - Surveillance,

Prevention and Treatment,

a section of the journal

Frontiers in Medicine

Received: 15 May 2020

Accepted: 22 June 2020

Published: 03 July 2020

Citation:

Kantor BN and Kantor J (2020) Non-pharmaceutical Interventions for

Pandemic COVID-19: A

Cross-Sectional Investigation of US General Public Beliefs, Attitudes, and

Actions. Front. Med. 7:384.

doi: 10.3389/fmed.2020.00384

\section{Non-pharmaceutical Interventions for Pandemic COVID-19: A Cross-Sectional Investigation of US General Public Beliefs, Attitudes, and Actions}

\author{
Bella Nichole Kantor ${ }^{1}$ and Jonathan Kantor ${ }^{2,3,4,5 *}$ \\ ${ }^{1}$ Harvard Extension School, Harvard University, Cambridge, MA, United States, ${ }^{2}$ Center for Global Health, University of \\ Pennsylvania Perelman School of Medicine, Philadelphia, PA, United States, ${ }^{3}$ Center for Clinical Epidemiology and \\ Biostatistics, University of Pennsylvania Perelman School of Medicine, Philadelphia, PA, United States, ${ }^{4}$ Department of \\ Dermatology, University of Pennsylvania Perelman School of Medicine, Philadelphia, PA, United States, ${ }^{5}$ Florida Center for \\ Dermatology, P.A., St Augustine, FL, United States
}

Non-pharmaceutical interventions (NPIs) represent the primary mitigation strategy for the COVID-19 pandemic. Despite this, many government agencies and members of the general public may be resistant to NPI adoption. We sought to understand public attitudes and beliefs regarding various NPIs and self-reported adoption of NPIs, and to explore associations between NPI performance and the baseline characteristics of respondents. We performed a cross-sectional age-, sex-, and race- stratified survey of the general US population. Of the 1,005 respondents, 37\% (95\% Cl 34.0, 39.9) felt that NPIs were inconvenient, while only $0.9 \%(95 \% \mathrm{Cl} 0.3,1.5)$ of respondents believed that NPIs would not reduce their personal risk of illness. Respondents were most uncertain regarding the efficacy of mask and eye protection use, with 30.6 and $22.1 \%$, respectively, unsure whether their use would slow disease spread. On univariate logistic regression analyses, NPI adherence was associated with a belief that NPIs would reduce personal risk of developing COVID-19 [OR 3.06, 95\% Cl [1.25, 7.48], $p=0.014$ ] and with a belief that NPIs were not difficult to perform [OR 1.79, 95\% Cl [1.38, 2.31], $p<0.0001$ ]. Respondents were compliant with straightforward, familiar, and heavily-encouraged NPI recommendations such as hand-washing; more onerous approaches, such as avoiding face touching, disinfecting surfaces, and wearing masks or goggles, were performed less frequently. NPI non-adherence is associated with both outcome expectations (belief that NPIs are effective) and process expectations (belief that NPIs are not overly inconvenient); these findings have important implications for designing public health outreach efforts, where the feasibility, as well as the effectiveness, of NPIs should be stressed.

Keywords: COVID- 19, non-pharmaceutical interventions, SARS-CoV-2, quarantine, public attitudes 


\section{INTRODUCTION}

Non-pharmaceutical interventions (NPIs) have emerged as a first line of protection and mitigation in the face of the SARS-CoV2 infection pandemic, particularly given the evidence suggesting the efficacy of such interventions in previous pandemics $(1,2)$. Since modern NPIs were adopted over a century ago during the 1918-1919 flu pandemic, much of the public debate has remained unchanged, centering on the efficacy and burdensomeness of NPIs, and their potential for broader effects on morale and economic stability $(3,4)$.

Public perceptions of NPIs may be an important determinant of compliance (5-9). Moreover, the intensity of public scrutiny surrounding COVID-19 NPI adoption may further heighten the importance of public buy-in in developing meaningful and robust public health solutions (10-13). Public adoption of NPIs may also be region-specific, as one study demonstrated significant variation in willingness to use NPIs in response to Severe Acute Respiratory Syndrome (SARS) outbreaks that may be of cultural origin (14). Others have explored the efficacy of various NPIs in response to a range of emerging infectious diseases, including swine flu, and Ebola $(15,16)$. Pandemic responsiveness is contingent on individuals eschewing their normal daily behaviors; thus, a small number of refusers may drive-and social media may further exacerbate-such behaviors. Some have suggested that NPI adherence is improved with improved communication; that is, NPI non-adherence is the result of a knowledge gap (17-25). Yet data from behavioral research suggests that non-compliance with expert recommendations is sometimes not a result of a lack of knowledge per se (26-31).

Understanding whether outcome expectations (a perception of efficacy) affect NPI adherence is critical; if there is a knowledge gap in appreciating that NPIs are effective, it could be addressed through outreach efforts. Conversely, if NPI non-adherence is a function of process expectations (concerns that performing NPIs is too onerous), then outreach efforts could be focused on mitigating these perceptions rather than highlighting the potential to reduce disease spread.

We therefore sought to understand public attitudes and beliefs regarding various NPIs and self-reported adoption of NPIs, and to explore associations between NPI performance and the baseline characteristics of respondents. These data may help inform public health efforts, as a better understanding of the drivers of refusal to engage in NPIs will help tailor messaging appropriately and ideally increase the chances of encouraging behavioral changes that may ultimately result in reduced disease transmission.

\section{METHODS}

We developed a cross-sectional online survey of the general US population after iterative pilot testing. This study was deemed exempt by the Ascension Health institutional review board. The survey was prepared on the Qualtrics platform (Qualtrics
Corp, Provo, Utah) and distributed to a representative US sample stratified by age, sex, and race, through Prolific Academic (Oxford, United Kingdom), a platform for academic survey research (32). Prolific Academic maintains a database of over 100,000 potential survey respondents, approximately one-third of whom reside in the US $(10,33)$. By stratifying on age, race, and sex, the company is able to provide a representative sample of the US general population. Respondents were rewarded with a small payment $(<\mathrm{US} \$ 1)$. Subjects provided consent and were allowed to terminate the survey at any time, and all responses were confidential. Sample size calculations were performed a priori for a separate study using this dataset to study mental health outcomes in the COVID-19 pandemic (34); post hoc sample size calculations demonstrated that a sample size of 1,000 respondents would yield $95 \%$ confidence intervals with a clinically meaningful margin of error of $\pm 3.1 \%$ when taking the entire adult population of the US as our population of interest.

Baseline responses to survey questions were recorded, and demographic information was self-reported by respondents. Responses to a range of questions regarding attitudes to the COVID-19 pandemic, fears, worries, and NPI beliefs and actions were collected using Likert scales. These questions were developed and refined de novo using iterative online focus group testing. Key questions addressed included NPI performance/ adherence over the past week (with Likert-type responses), beliefs regarding the efficacy of individual NPIs in slowing the spread of COVID-19 (with Likert-type response options), and stated beliefs regarding whether adherence to NPIs would reduce the personal likelihood of contracting COVID-19 (with Likerttype responses).

$T$-tests and chi-squared tests were seen as appropriate for baseline continuous and categorical variables. Subgroup comparisons of non-normally distributed data were performed using the Kruskal Wallis test. Univariate logistic regression odds ratios of association were assessed between the dependent variable of NPI adherence, defined as those who engaged, on average, in each NPI always or most of the time, and baseline characteristics and attitudes. Statistical analyses were performed using Stata 13 for Mac (College Station, Texas).

\section{RESULTS}

Of the 1,020 subjects who were recruited, 1,005 finished the survey, yielding a completion rate of $98.5 \%$. The mean (SD) age of respondents was 45 (16), and $494(48.8 \%)$ of the respondents were male; baseline respondent characteristics are outlined in Table 1. Surveys were returned between March 29 and March 31, 2020; by this time, the federal government had already issued nationwide social distancing guidelines and 35 states had already enacted stay-at-home orders of some sort.

More than $90 \%$ of subjects reported using several common NPIs either all or most of the time (Table 2). Respondents were most uncertain regarding the efficacy of mask and eye protection 
TABLE 1 | Demographic and baseline characteristics of respondents, overall and by social distancing adherence, and whether respondents were under a government requirement to remain at home.

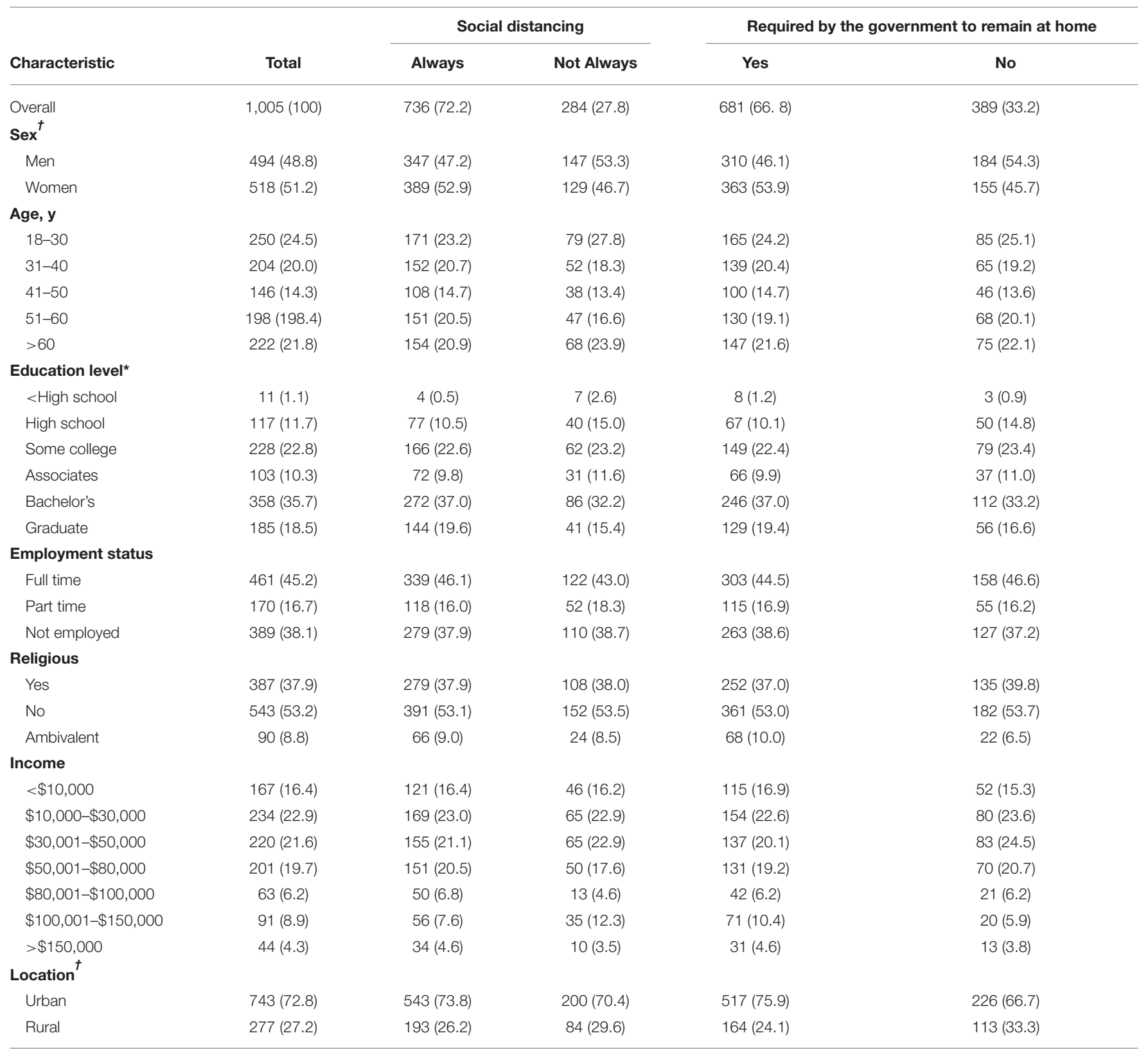

All values are listed as number (\%).

* $p<0.05$ by chi squared test (social distancing).

${ }^{\dagger} p<0.05$ by chi squared test (required to stay at home).

use, with 30.6 and $22.1 \%$, respectively, unsure whether their use would slow disease spread. Overall, $37 \%(34.0,39.9)$ of respondents felt that NPIs in general were difficult to perform (or inconvenient), while only $0.9 \%(0.3,1.5)$ of respondents believed that NPIs in general would not reduce their personal risk of illness.

On univariate logistic regression analyses, NPI adherence was associated with a belief that NPIs would reduce personal risk of developing COVID-19 [OR 3.06, 95\% CI [1.25, 7.48], $p=$
0.014] and with a belief that the NPIs were not difficult to perform [OR 1.79, 95\% CI [1.38, 2.31], $p<0.0001]$. Adherence was also associated with self-described religiosity [OR 1.85, 95\% CI [1.42, 2.39], $p<0.0001]$; full-time employment [OR 1.35, $95 \%$ CI $[1.02,1.78], p=0.035]$; worry regarding a family member contracting COVID-19 [OR 1.47, 95\% CI [1.11, 1.93], $p=0.007]$; and belief that the media was not exaggerating the severity of the pandemic [OR 1.44, 95\% CI [1.09, 1.91], $p=0.012]$. 
TABLE 2 | Non-pharmaceutical intervention performance frequency and belief level.

\begin{tabular}{|c|c|c|c|c|c|c|c|c|c|c|}
\hline \multirow[b]{2}{*}{ NPI } & \multicolumn{5}{|c|}{ Performed in last week, frequency, $n(\%)$} & \multicolumn{5}{|c|}{ Slows the Spread of COVID-19, level of agreement, $n(\%)$} \\
\hline & Always & Most of the time & Sometimes & Rarely & Never & $\begin{array}{l}\text { Completely } \\
\text { agree }\end{array}$ & Agree & Unsure & Disagree & $\begin{array}{l}\text { Disagree } \\
\text { completely }\end{array}$ \\
\hline Hand washing & $776(77.2)$ & $188(18.7)$ & $29(2.9)$ & $9(0.9)$ & $3(0.3)$ & $871(86.7)$ & $124(12.3)$ & $9(0.9)$ & $0(0)$ & $1(0.1)$ \\
\hline Hand sanitizer & $355(35.6)$ & $192(19.3)$ & $222(22.3)$ & $95(9.5)$ & $132(13.3)$ & 722 (71.9) & 224 (22.3) & $45(4.5)$ & $7(0.7)$ & $6(0.6)$ \\
\hline $\begin{array}{l}\text { Avoiding } \\
\text { handshakes }\end{array}$ & $875(87.2)$ & $67(6.7)$ & $42(4.2)$ & $9(0.9)$ & $10(1.0)$ & 819 (81.9) & $164(16.4)$ & $13(1.3)$ & $2(0.2)$ & $2(0.2)$ \\
\hline $\begin{array}{l}\text { Tissue/ elbow } \\
\text { sneeze }\end{array}$ & 749 (74.6) & $170(16.9)$ & $50(5.0)$ & $19(1.9)$ & $16(1.6)$ & 793 (78.9) & 189 (18.9) & $20(2.0)$ & $2(0.2)$ & $1(0.1)$ \\
\hline $\begin{array}{l}\text { Avoiding face } \\
\text { touching }\end{array}$ & $247(24.6)$ & $356(35.4)$ & $282(28.1)$ & $86(8.6)$ & $34(3.4)$ & 748 (74.6) & $207(20.7)$ & $42(4.2)$ & $5(0.5)$ & $1(0.1)$ \\
\hline Disinfecting surfaces & $347(34.7)$ & 293 (29.3) & $242(24.2)$ & $67(6.7)$ & $52(5.2)$ & $745(74.2)$ & $223(22.2)$ & $28(2.8)$ & $5(0.5)$ & $3(0.3)$ \\
\hline Wearing mask & $71(7.1)$ & $40(4.0)$ & $95(9.5)$ & 109 (10.9) & $687(68.6)$ & 420 (41.9) & $234(23.4)$ & $221(22.1)$ & $89(8.9)$ & $38(3.8)$ \\
\hline $\begin{array}{l}\text { Wearing eye } \\
\text { protection }\end{array}$ & $77(7.7)$ & $45(4.5)$ & $65(6.5)$ & $102(10.2)$ & 709 (71.0) & 360 (35.9) & $187(18.6)$ & 307 (30.6) & $106(10.6)$ & $43(4.3)$ \\
\hline Social distancing & 736 (73.3) & $215(21.4)$ & $35(3.5)$ & $12(1.2)$ & $6(0.6)$ & $856(85.9)$ & $123(12.3)$ & $12(1.2)$ & $3(0.3)$ & $3(0.3)$ \\
\hline Avoiding travel & 767 (76.6) & $171(17.1)$ & $44(4.4)$ & $7(0.7)$ & $12(1.2)$ & $835(83.1)$ & $147(14.6)$ & $19(1.9)$ & $1(0.1)$ & $3(0.3)$ \\
\hline $\begin{array}{l}\text { Required to stay at } \\
\text { home/ quarantine }\end{array}$ & $582(58.0)$ & $318(31.7)$ & $64(6.4)$ & $22(2.2)$ & $18(1.8)$ & $846(84.4)$ & 135 (13.5) & $18(1.8)$ & $0(0)$ & $4(0.4)$ \\
\hline
\end{tabular}

All performance-belief pairs were associated significantly ( $p<0.001)$.

\section{DISCUSSION}

Most respondents stated that they were performing key NPIs, such as hand washing and social distancing, on a consistent basis, and the majority of respondents agreed that NPIs are effective in slowing the spread of COVID-19. Mask wearing and eye protection adherence and perceived efficacy lag behind other NPIs; this may be due to messaging, since at the time the survey was performed no recommendations were in place to encourage mask or face protection by the general public in the US. While some have questioned the effectiveness of school closures (35), it is important to maintain consistent messaging for the general public, particularly since the scientific consensus is that NPIs are effective overall $(2,5,6)$. This is particularly important since beyond belief in efficacy, emotional appeals may be important in encouraging appropriate behaviors (36). Not surprisingly, those who believe that NPI use is not at all difficult to engage in/inconvenient are more likely to engage in NPI use, as are those that believe in the efficacy of NPIs in reducing personal risk of COVID-19 infection. Our single study incudes approximately the same number of subjects as all 16 studies included in a recent systematic review of influenza pandemic beliefs (37).

Limitations of this survey-based study include: generalizability, mitigated in part by the stratified sampling and large survey panel design; response and social desirability biases, the latter reduced by the anonymous nature of the survey; and the inability to draw causal inferences from a cross-sectional investigation.

These data highlight potential targets for public health efforts: respondents were compliant with straightforward, familiar, and heavily-encouraged NPI recommendations such as hand-washing; more onerous approaches, such as avoiding face touching, disinfecting surfaces, and wearing masks or goggles, were performed less frequently. These findings are consistent with previous research on NPIs for pandemic influenza (6). Changes in CDC recommendations for mask/ face coverings may impact these behaviors in the future.

Given these findings, several steps could be considered to encourage future NPI adoption. First, make it clear: consistent messaging from the government and other community leaders on the effectiveness of NPIs may lower the threshold for community buy-in. The public should understand that NPIs have an effect on their personal risk of contracting COVID-19, as well as the risk of others becoming infected. Second, make it easy: compliance with NPIs should not be onerous. This applies to both practical aspects of NPI adherence-masks and hand sanitizer must be easily and, ideally, freely available-as well as to the social underpinnings of NPI adherence. One study previously demonstrated that the public in countries where wearing masks is de rigueur are more likely to engage in mask wearing in response to a pandemic (14). Thus, highlighting that mask-wearing (and other NPIs) are socially expected, rather than socially awkward, may be helpful.

An improved understanding of the drivers of refusal to engage in NPIs may help tailor messaging and increase the chances of eliciting behavioral change. NPI nonadherence is associated with both outcome expectations (NPIs are effective) and process expectations (NPIs are inconvenient). These findings have important implications for designing public health outreach efforts, where the feasibility, as well as the effectiveness, of NPIs should be stressed. 


\section{DATA AVAILABILITY STATEMENT}

The raw data supporting the conclusions of this article will be made available by the authors, without undue reservation.

\section{ETHICS STATEMENT}

The studies involving human participants were reviewed and approved by Ascension Health IRB. The ethics committee waived the requirement of written informed consent for participation.

\section{REFERENCES}

1. Parodi SM, Liu VX. From containment to mitigation of COVID-19 in the US. JAMA. (2020) 323:1441-2. doi: 10.1001/jama.2020.3882

2. Hatchett RJ, Mecher CE, Lipsitch M. Public health interventions and epidemic intensity during the 1918 influenza pandemic. Proc Natl Acad Sci USA. (2007) 104:7582. doi: 10.1073/pnas.0610941104

3. Markel H, Lipman HB, Navarro JA, Sloan A, Michalsen JR, Minna Stern A, et al. Nonpharmaceutical interventions implemented by US cities during the 1918-1919 influenza pandemic. JAMA. (2007) 298:64454. doi: 10.1001/jama.298.6.644

4. Aledort J, Lurie N, Wasserman J, Bozzette S. Non-pharmaceutical public health interventions for pandemic influenza: an evaluation of the evidence base. BMC Public Health. (2007) 7:208. doi: 10.1186/1471-2458-7-208

5. Aiello AE, Coulborn RM, Aragon TJ, Baker MG, Burrus BB, Cowling BJ, et al. Research findings from nonpharmaceutical intervention studies for pandemic influenza and current gaps in the research. AJIC. (2010) 38:2518. doi: 10.1016/j.ajic.2009.12.007

6. Vukotich CJ, Coulborn RM, Aragon TJ, Baker MG, Burrus BB, Aiello AE, et al. Findings, gaps, and future direction for research in nonpharmaceutical interventions for pandemic influenza. Emerg Infect Dis. (2010). 16:e2. doi: 10.3201/eid1604.090719

7. Stebbins S, Downs JS, Vukotich CJ. Using nonpharmaceutical interventions to prevent influenza transmission in elementary school children: parent teacher perspectives. J Public Health Manag Pract. (2009) 15:112. doi: 10.1097/01.PHH.0000346007.66898.67

8. Koonin LM, Cetron MS, Pollard WE, Cetron MS, Pollard WE, Mitchell EW, et al. Public response to community mitigation measures for pandemic influenza. Emerg Infect Dis. (2008) 14:778-6. doi: 10.3201/eid1405.071437

9. Cowling BJ, Lam TT-Y, Yen H-L, Poon LLM, Peiris M. Evidence-based options for controlling respiratory virus transmission. Emerg Infect Dis. (2017) 23. doi: 10.3201/eid2311.171231

10. Eysenbach G, Iyawa GE, Bahrami MA, Geldsetzer P. Use of rapid online surveys to assess people's perceptions during infectious disease outbreaks: a cross-sectional survey on COVID-19. J Med Internet Res. (2020) 22:e18790. doi: 10.2196/18790

11. Geldsetzer P. Knowledge and perceptions of COVID-19 among the general public in the united states and the united kingdom: a cross-sectional online survey. Ann Internal Med. (2020). doi: 10.7326/M20-0912. [Epub ahead of print].

12. Cowling BJ, Ali ST, Ng TWY, Tsang TK, Li JCM, Fong MW, et al. Impact assessment of non-pharmaceutical interventions against coronavirus disease 2019 and influenza in Hong Kong: an observational study. Lancet Public Health. (2020) 5:e279-88. doi: 10.1016/S2468-2667(20)30090-6

13. Cowper A. Covid-19: are we getting the communications right? BMJ. (2020) 368:m919. doi: 10.1136/bmj.m919

14. Matthews Pillemer F, Blendon RJ, Zaslavsky AM, Lee BY. Predicting support for non-pharmaceutical interventions during infectious outbreaks: a four region analysis. Disasters. (2015) 39:125-45. doi: 10.1111/disa.12089

15. Peak CM, Childs LM, Grad YH, Buckee CO. Comparing nonpharmaceutical interventions for containing emerging epidemics. Proc Natl Acad Sci USA. (2017) 114:4023. doi: 10.1073/pnas.1616438114

\section{AUTHOR CONTRIBUTIONS}

JK and BK: study conception, statistical analysis, survey development, and manuscript preparation. JK: oversight. All authors contributed to the article and approved the submitted version.

\section{ACKNOWLEDGMENTS}

This manuscript has been released as a pre-print at https://www. medrxiv.org/content/10.1101/2020.04.26.20078618v1 (14).

16. Cowling BJ, Ng DMW, Ip DKM, Liao Q, Lam WWT, JT Wu, et al. Community psychological and behavioral responses through the first wave of the 2009 influenza A(H1N1) pandemic in Hong Kong. J Infect Dis. (2010) 202:867. doi: 10.1086/655811

17. Bish A, Michie S. Demographic, and attitudinal determinants of protective behaviours during a pandemic: a review. Br J Health Psychol. (2010) 15:797824. doi: 10.1348/135910710X485826

18. Rubin GJ, Amlot R, Page L, Wessely S. Public perceptions, anxiety, and behaviour change in relation to the swine flu outbreak: cross sectional telephone survey. BMJ. (2009) 339:b2651. doi: 10.1136/bmj.b2651

19. Lau JTF, Kim JH, Tsui H, Griffiths S. Perceptions related to human avian influenza and their associations with anticipated psychological and behavioral responses at the onset of outbreak in the Hong Kong Chinese general population. Am J Infect Control. (2007) 35:38-49. doi: 10.1016/j.ajic.2006.07.010

20. Lau JTF, Kim JH, Tsui HY, Griffiths S. Perceptions related to bird-to-human avian influenza, influenza vaccination, and use of face mask. Infection. (2008) 36:434-43. doi: 10.1007/s15010-008-7277-y

21. Lau JTF, Kim JH, Tsui HY, Griffiths S. Anticipated and current preventive behaviors in response to an anticipated human-to-human H5N1 epidemic in the Hong Kong Chinese general population. BMC Infect Dis. (2007) 7:18. doi: 10.1186/1471-2334-7-18

22. Lau JTF, Yang X, Tsui H, Kim JH. Monitoring community responses to the SARS epidemic in Hong Kong: from day 10 to day 62. J Epidemiol Commun Health. (2003) 57:864-70. doi: 10.1136/jech.57.11.864

23. Lau JTF, Yang XL, Tsui HY, Pang E. SARS related preventive and risk behaviours practised by Hong Kong-mainland China cross border travellers during the outbreak of the SARS epidemic in Hong Kong. J Epidemiol Commu Health. (2004) 58:988-96. doi: 10.1136/jech.2003.017483

24. Lau JTF, Yang XL, Tsui HY, Pang E, Kim JH. SARS preventive and risk behaviours of Hong Kong air travellers. Epidemiol Infect. (2004) 132:72736. doi: 10.1017/S0950268804002225

25. Stern A, Cetron M, Markel H. Closing the schools: lessons from the 1918-19 U.S. influenza pandemic. Health Affairs. (2009) 28:W106678. doi: 10.1377/hlthaff.28.6.w1066

26. Tang CSK, Wong CY. An outbreak of the severe acute respiratory syndrome: Predictors of health behaviors and effect of community prevention measures in Hong Kong, China. Am J Public Health. (2003) 93:18878. doi: 10.2105/AJPH.93.11.1887

27. Tang CSK, Wong CY. Psychosocial factors influencing the practice of preventive behaviors against the severe acute respiratory syndrome among older chinese in Hong Kong. J Aging Health. (2005) 17:490506. doi: 10.1177/0898264305277966

28. Tang CSK, Wong CY. Factors influencing the wearing of facemasks to prevent the severe acute respiratory syndrome among adult Chinese in Hong Kong. Preve Med. (2004) 39:1187-93. doi: 10.1016/j.ypmed.2004.04.032

29. Grinbaum A. Cognitive barriers in perception of nanotechnology. J Law Med Ethics. (2006) 34:689-94. doi: 10.1111/j.1748-720X.2006.00088.x

30. Sisk BA, Mack JW, DuBois J. Knowing versus doing: the value of behavioral change models for emotional communication in oncology. Patient Educ Counsel. (2019) 102:pp2344-8. doi: 10.1016/j.pec.2019. 07.023 
31. Drummond C, Fischhoff B. Individuals with greater science literacy education have more polarized beliefs on controversial science topics. Proc Natl Acad Sci USA. (2017) 114:9587-92. doi: 10.1073/pnas.1704882114

32. Peer E, Brandimarte L, Samat S, Acquisti A. Beyond the Turk: Alternative platforms for crowdsourcing behavioral research. J Exp Soc Psychol. (2017). 70:153-63. doi: 10.1016/j.jesp.2017.01.006

33. Explore Our Participant Pool Demographics. (2020). Available online at: https://www.prolific.co/demographics/ (accessed June 5, 2020).

34. Kantor BN, Kantor J. Mental health outcomes and associations during the coronavirus disease 2019 pandemic: a crosssectional survey of the US general population. medRxiv. (2020) 2020:2020.2005.2026.20114140. doi: 10.1101/2020.05.26.20114140

35. Davis BM, Markel H, Navarro A, Wells E, Monto AS, Aiello AE. The effect of reactive school closure on community influenza-like illness counts in the state of michigan during the (2009) H1N1 pandemic. Clin Infect Dis. (2015). 60:e90-7. doi: 10.1093/cid/civ182

36. Liu BF, Kim S. How organizations framed the (2009). H1N1 pandemic via social and traditional media: Implications for U.S. health communicators. Public Relat Rev. (2011) 37:233-44. doi: 10.1016/j.pubrev.2011.03.005
37. Teasdale E, Santer M, Geraghty AWA, Little P, Yardley L. Public perceptions of non-pharmaceutical interventions for reducing transmission of respiratory infection: systematic review and synthesis of qualitative studies. BMC Public Health. (2014) 14:589-9. doi: 10.1186/1471-2458-14-589

38. Kantor BN, Kantor J. Nonpharmaceutical interventions for pandemic COVID-19: A cross-sectional investigation of US general public beliefs, attitudes, and actions. medRxiv. (2020) 2020:2020.2004.2026.20078618. doi: 10.1101/2020.04.26.20078618

Conflict of Interest: The authors declare that the research was conducted in the absence of any commercial or financial relationships that could be construed as a potential conflict of interest.

Copyright (c) 2020 Kantor and Kantor. This is an open-access article distributed under the terms of the Creative Commons Attribution License (CC BY). The use, distribution or reproduction in other forums is permitted, provided the original author(s) and the copyright owner(s) are credited and that the original publication in this journal is cited, in accordance with accepted academic practice. No use, distribution or reproduction is permitted which does not comply with these terms. 